\title{
Electro-Kinetic Technology as a Low-Cost Method for Dewatering Food By-Product
}

\author{
Sing K. Ng, ${ }^{1}$ Andrew Plunkett, ${ }^{1}$ Valentina Stojceska, ${ }^{1}$ Paul Ainsworth, ${ }^{1}$ \\ John Lamont-Black, ${ }^{2}$ Jean Hall, ${ }^{3}$ Chris White, ${ }^{3}$ Stephanie Glendenning, ${ }^{3}$ and \\ David Russell ${ }^{4}$ \\ ${ }^{1}$ Department of Food and Tourism Management, Manchester Metropolitan University, \\ Manchester, UK \\ ${ }^{2}$ Electrokinetic Ltd., Newcastle University, Newcastle upon Tyne, UK \\ ${ }^{3}$ Civil Engineering Department, Newcastle University, Newcastle upon Tyne, UK \\ ${ }^{4}$ Bioscience Network Limited, Roslin, Midlothian, UK
}

\begin{abstract}
Increasing volumes of food waste, intense environmental awareness, and stringent legislation have imposed increased demands upon conventional food waste management. Food byproducts that were once considered to be without value are now being utilized as reusable materials, fuels, and energy in order to reduce waste. One major barrier to the valorization of food by-products is their high moisture content. This has brought about the necessity of dewatering food waste for any potential re-use for certain disposal options. A laboratory system for experimentally characterizing electro-kinetic dewatering of food by-products was evaluated. The bench scale system, which is an augmented filter press, was used to investigate the dewatering at constant voltage. Five food by-products (brewer's spent grain, cauliflower trimmings, mango peel, orange peel, and melon peel) were studied. The results indicated that electro-kinetic dewatering combined with mechanical dewatering can reduce the percentage of moisture from $78 \%$ to $71 \%$ for brewer's spent grain, from $77 \%$ to $\mathbf{6 8 \%}$ for orange peel, from $80 \%$ to $73 \%$ for mango peel, from $91 \%$ to $74 \%$ for melon peel, and from $92 \%$ to $80 \%$ for cauliflower trimmings. The total moisture reduction showed a correlation with electrical conductivity $\left(R^{2}=0.89\right)$. The energy consumption of every sample was evaluated and was found to be up to 60 times more economical compared to thermal processing.
\end{abstract}

Keywords Dewatering; Electro-kinetic technology; Food waste; Low-cost method

\section{INTRODUCTION}

The amount of food waste in the UK has been estimated at about 138,000 tonnes in $2006 .^{[1]}$ A key priority of the food industry is to divert processing waste streams away

Correspondence: Valentina Stojceska, Department of Food and Tourism Management, Manchester Metropolitan University, Old Hall Lane, Manchester, M14 6HR, UK; E-mail: V.Stojceska@mmu.ac.uk from landfill sites because most of the food waste is essentially biodegradable. Stringent legislation such as Article (5) section 2 of the European Union Directive $1999 / 31 / E C$ now requires the reduction of municipal biodegradable materials going into landfills to $50 \%$ by 2009 and $35 \%$ by 2016 . As a result of that, land-filling large volumes of food waste is becoming an increasingly expensive disposal option, making waste minimization more attractive than ever. A major barrier to the valorization of food waste was the need to reduce its high water content before further extrusion processing, ${ }^{[2,3]}$ which resulted in the relatively expensive energy costs for the entire of the processing, ${ }^{[4]}$ making up approximately $90 \%$ of the total cost.

There are established dewatering techniques available to dewater wastes using mechanical, ${ }^{[5]}$ compressional and centrifugal forces, ${ }^{[6]}$ gravitational, and thermal. ${ }^{[7-9]}$ A number of studies have investigated methods of optimizing and improving the efficiency of traditional convective drying methods; for example, Beke et al. ${ }^{[10]}$ examined the effects of time, temperature, airflow rate, and product properties on the drying of grains, and suggested a range of optimal conditions depending upon the product characteristics. Grabowski et al. ${ }^{[1]}$ had a different approach to improving the efficiency of convective drying, combining it with osmotic drying when drying grapes in a fluidized bed drier. They found that the drying time could be reduced by a factor of 1.5, when compared to convective drying alone, and had benefits in terms of improved product quality.

Electro-kinetic (EK) dewatering involves the application of a low electric potential across the waste layers that need to be dewatered, which has a great potential to be a simple and efficient way to not only dewater but also to accelerate the dewatering of food wastes. It involves application of a constant voltage (DC) across of pair electrodes placed 
across a volume of solid/liquid slurry. The application of this electric field causes several effects including electromigration, electro-osmosis, changes in $\mathrm{pH}$, and electrophoresis. ${ }^{[12-14]}$ Electro-osmosis is the most critical process for the successful dewatering of food suspensions such as grape,${ }^{[11]}$ vegetable sludge,${ }^{[15]}$ tomato paste,${ }^{[16]}$ cauliflower, mushroom and green pea. ${ }^{[17]}$

Electro-kinetic dewatering is typically ten-fold more energy efficient than thermal dewatering ${ }^{[18]}$ but it has not been widely used commercially in food waste management, probably due to the process development costs and lack of understanding of the technology. Reducing the cost of dewatering could greatly facilitate the utilization of waste food material. Therefore, the objective of this study was to investigate the combined electro-kinetic and mechanical dewatering process under constant voltage conditions in order to enhance drying of food by-products and reduce costs.

Brewer's spent grain (BSG) is an example of a food by-product from the brewing industry. Because of its high moisture and fermentable sugar content, it becomes an environmental problem after a short time (7-10 days). ${ }^{[19]}$ Due to the large continuous supply at relatively low cost and a potentially high nutritional value, if dried, BSG can be considered as an attractive adjunct to human food.

Oranges constitute the bulk of citrus fruit production, accounting for more than half of global production in $2004 .{ }^{[20]}$ A large portion of this production is addressed to the industrial extraction of citrus juice, which leads to huge amounts of high moisture waste material. This material residue produces odor and soil pollution if disposed into landfills and represents a major problem for the industries involved. ${ }^{[21,22]}$

In 2005, world production of mango was estimated at 28.51 million metric tons. Mangoes are produced in over 90 countries worldwide with Asia accounting for approximately $77 \%$ of global mango production, and with the Americas and Africa accounting for approximately 13\% and $9 \%$, respectively. ${ }^{[23]}$ Peel constitutes $15-20 \%$ of the total fruit and its disposal is a major problem causing environmental pollution. ${ }^{[24]}$

Cauliflower has a very high waste index whereby almost $50 \%$ (stems and the outer leaves) of the plant is trimmed and removed during harvesting. Cauliflower trimmings are an excellent source of protein (16.1\%), cellulose $(16 \%)$, and hemicellulose $(8 \%) .{ }^{[25]}$ They are considered as a rich source of antioxidants and dietary fiber and it possesses both antioxidant and anti-carcinogenic properties. ${ }^{[3]}$

Today's predominant melon varieties include watermelon, cantaloupe, and honey dew. The largest producer of cantaloupes and other melons in 2004 was China, accounting over for $50 \%$ of world production by weight, followed by Turkey with $6.1 \%$, Iran with $4.4 \%$, the U.S. with $4.2 \%$, and Spain with $3.9 \% .{ }^{[23]}$ Melons are often consumed as desserts, snacks, in fruit salad, and for breakfast. Recently, marketing strategies by the food industry have focused on packed pre-cut product and in-store salad bars to appeal to consumers. These attempts have shifted melon waste from the conventional household waste to food industry waste and the amount produced is ever increasing.

\section{METHODS}

\section{Sample Preparation}

Five different types of food co-product were used. Brewer's spent grain was supplied by Holts Brewery, Manchester. Orange, mango, and melon peel were supplied by Orchard House Foods Ltd., UK. Cauliflower trimmings were obtained from a local wholesaler. Each waste was homogenized using a Tecator 1094 homogenizer for 1 minute, divided into $1 \mathrm{~kg}$ samples, and kept chilled at $4{ }^{\circ} \mathrm{C}$ in a sealed plastic bag until used. Samples were taken from the fridge, one at a time when required, and left to reach room temperature for 24 hours before dewatering trials. Determinations were performed in triplicate and mean values reported. The coefficient variation was less than $10 \%$.

\section{Food By-Products Proximate Analysis}

In this study, the $\mathrm{pH}$ was determined by $\mathrm{pH}$ meter (PS6 Poolpro, Myron L Company), moisture content by air oven method ${ }^{[26]}\left(48 \mathrm{~h}\right.$ in air oven at $105^{\circ} \mathrm{C}$ to constant weight), crude protein content was calculated from total nitrogen content of the sample as measured by the Kjedahl method. The factor Nx6.25 was used to convert total $\mathrm{N}_{2}$ to crude protein, ${ }^{[26]}$ fat content by the Caviezel method for total fat determination (AOAC International PVM 4: 1997), ${ }^{[27]}$ ash was determined by combustion in a furnace at $550^{\circ} \mathrm{C}$ and weighing the residue; fiber was determined using a fiber test kit combination of enzymatic and gravimetric methods (Sigma-Aldrich, Inc., Saint Louis, MO)(AOAC 1997); electrical conductivity was carried out in accordance with 10.2 of BS.1377-3:1990 using the electrode disk method. ${ }^{[28]}$

\section{Electro-Kinetic Measurement \\ Electrode}

The EKG electrode was made by incorporating $1.0 \mathrm{~mm}$ diameter titanium-coated copper wires into the skin of a 2.0-mm-thick polyester woven filter cloth geotextile. The filter cloth had been cut into 141-mm-diameter discs in order to fit into the electro-osmotic cell as shown in Figure 1. Titanium wires were coated in a mixed metal oxide to curb electrode corrosion associated with conventional EK dewatering. The wire spacing was made as small as practically possible at $7.5 \mathrm{~mm}$ center to center to improve the uniformity of the electric field applied to the sample. The resulting electrode has combined electrical 


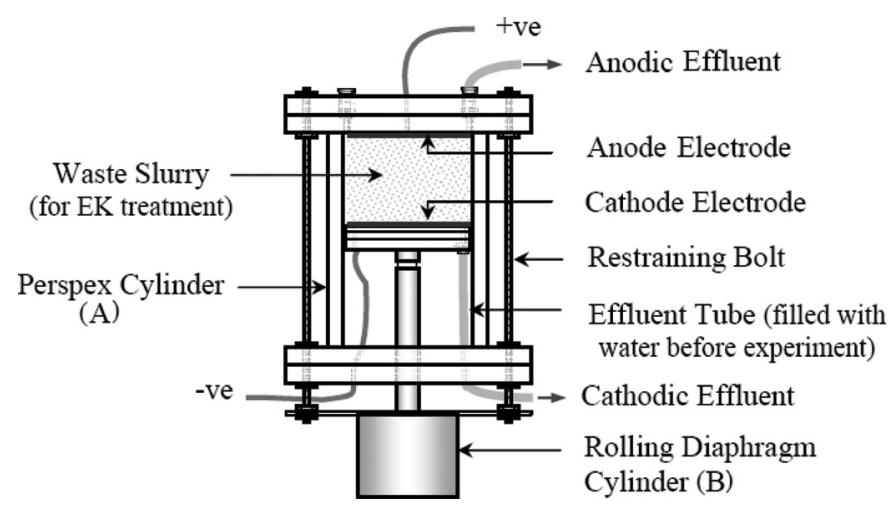

FIG. 1. Schematic of apparatus for combined electro-osmosis and mechanical pressure dewatering.

conducting and filtration functions. For each electrode assembly, all of the wire ends were folded behind the filter cloth, joined and then connected to an insulated copper wire leading to the power supply. The electrode unit was fastened to a perspex disc $(41.5 \mathrm{~mm}$ thick and $141.0 \mathrm{~mm}$ in diameter). Two sets of electrode assemblies were made to be installed above and below the material in the test cell ensuring a good electrical contact with the material under test.

\section{Test Cell}

Experiments were conducted in the purpose-built laboratory-scale EK dewatering cell shown in Figure 1, which consists of two main parts: (A) a cylindrical Perspex specimen compartment ( $236 \mathrm{~mm}$ long and $143 \mathrm{~mm}$ in diameter) to contain the sample; the compartment was both water- and air-tight so that effluent water and gas volumes could be measured; and (B) a piston connected to a rolling diaphragm cylinder for application of a back pressure. In this way, the cell could be used to assess both mechanical and EK dewatering functions. The cell was made of Perspex because of its chemical resistance to the acid and alkali environments generated by the electrode reactions and to allow visual observation of specimens during testing. The cell assembly had electrodes sandwiching the specimen to be treated, thereby replicating a filter press.

\section{Experiment Procedure}

The cathode electrode assembly was mounted inside the cell to allow free vertical movement. For each test material, $500 \mathrm{~g}$ of the respective food by-product was placed in the electro-osmotic cell, which gave an approximate depth of $50 \mathrm{~mm}$. The specimen thickness was considered to be realistic for this application; thicker samples reduce potential gradients, resulting in lower dewatering rates and longer processing times. The anode electrode assembly was then firmly fixed above the waste sample, making the cell both water- and air-tight. A constant back pressure of $75 \mathrm{kPa}$ was then applied, by means of a pneumatic ram, at the base of the cathode assembly to ensure that both electrodes remained in contact with the slurry during dewatering. The ram was calibrated such that the input pressure, as read from an inline pressure gauge, could be directly interpreted as the pressure applied to the cell. The pressure applied simulated a modest mechanical loading typical of that provided by a commercial belt press. This pressure also represents a realistic surcharge loading of approximately $3.5 \mathrm{~m}$ of fill in an in-situ application. The energy used in applying pressure to the material during the dewatering trials was estimated based upon the volume displacement from the cell and hence distance travelled by the pneumatic ram (Equation 1).

$$
E=P \times \frac{V}{A}
$$

Where $\mathrm{E}=$ Energy $(\mathrm{J}), \mathrm{P}=$ Pressure $(\mathrm{kpa}), \mathrm{V}=$ Volume displacement of the cell $\left(\mathrm{m}^{3}\right), \mathrm{A}=$ Cross-sectional area of the cell $\left(\mathrm{m}^{2}\right)$.

The region behind the electrodes and the effluent tubes from the cell were filled with tap water so that as soon as effluent was produced during treatment it could be measured. The amount added in the tubes was $102 \mathrm{ml}$. The effluent tubes were then connected to measuring cylinders, while the copper wires from the electrodes were connected to the respective terminals of a constant DC power supply. The power supply was switched on while simultaneously opening the taps at the effluent outlets. In all experiments a processing time of 15 minutes was adopted. In each test the volume of effluent water was monitored throughout the test. The final moisture content of the press cakes was determined using the air oven methods. ${ }^{[26]}$ The $\mathrm{pH}$ of the effluent at the end of each test was also investigated. By measuring temporal electrical current into the cell, the electrical energy, $E(\mathrm{kWh})$, consumed during each experiment was determined using Equation (1).

$$
E=\int \frac{(V . I)}{1000} d t
$$

where $\mathrm{V}=$ voltage $(\mathrm{V}), \mathrm{I}=$ current $(\mathrm{A})$, and $\mathrm{t}=$ Processing time (h).

\section{Reproducibility and Statistical Analysis}

All the experiments were replicated, so that the data in the paper are all mean values of three tests with a coefficient of variation of less than $10 \%$. Statistically significant differences between values were determined at the $\mathrm{P}<0.05$ level using a multiple comparison test performed by SPSS 12.0.1 statistical analysis software (SPSS Inc., Chicago, IL) and correlation between parameters using Microsoft Excel 2002 (Microsoft Corporation, Sacramento, CA). 


\section{RESULTS AND DISCUSSION \\ Proximate Analysis}

The proximate analysis for each of the food by-products is listed in Table 1. Melon and cauliflower samples showed the highest electrical conductivity and moisture content. It seems the higher the moisture content the more potential there is to remove the moisture, thus decreasing the volume of waste. Similar findings were reported by Al-Asheh et al., ${ }^{[16]}$ who used an electroosmosis technique to dewater a tomato paste suspension. Whilst Al-Asheh et al. do not dwell on the composition of the sample being dewatered, they do highlight the role of antioxidants (lycopene in their study) in mopping up radicals generated as a result of electrolysis occurring during dewatering. The fruit and vegetable materials dewatered during this current study are known to contain significant levels of antioxidants (L-Ascorbic acid, Ferulic acid, etc.) and hence a similar effect would be anticipated. Spent grain is the least conductive but has the highest protein, fat, ash, and fiber content compared to the rest. In terms of $\mathrm{pH}$, the cauliflower sample showed the highest $\mathrm{pH}$ and the mango peel the lowest.

\section{Volume of Effluent Discharged}

Figure 2 shows the amount of effluent discharged from brewer's spent grain, melon, mango, orange, and cauliflower trimmings, for a specified voltage at 15 minutes elapsed time. This graph clearly shows the increase in the amount of effluent discharged when mechanical pressing $(0 \mathrm{~V})$ is augmented with an electrical field of 15 or $30 \mathrm{~V}$. The pressure applied during each measurement was kept constant at $75 \mathrm{kPa}$. The general increase in total effluent volume with increase in applied voltage observed in all the experiments can be explained by Ohms law, which states that the current flowing through a circuit is directly proportional to the applied voltage. Higher applied voltage increases the current density, which in effect increases the electrolytic and electro-osmotic processes within the cell. A study carried out on biomass ${ }^{[29]}$ showed that the efficiency of electro-kinetic dewatering is higher at lower voltages. This study showed that although the mass of water removed is greater at $50 \mathrm{~V}$ as compared to the lower voltage, the energy required to remove a unit mass of water by electro-kinetic will increase with voltage and thus reduces the total drying efficiency. This may be due to increased energy being wasted in Joule heating (specific heat capacity) and providing latent heat of vaporization for phase change of water at higher voltages. Controlling the temperature by regulating the applied voltage will result in more efficient usage of electrical energy. Al-Asheh et al. ${ }^{[16]}$ carried out studies both in constant current and constant voltage dewatering of tomato paste with their results showing little difference in the total amount of water removed at a given time. When compared with the results given in Figure 2, it is apparent that lower levels of water were removed after $15 \mathrm{~min}$. This may be accounted for by the absence of mechanical pressure being applied to the sample, i.e., the bed depth was maintained at a constant level. Al-Asheh et al. note marked differences in the water extraction rate when the bed depth is varied with a thinner bed showing higher rates of water removal. Thus the observed increased extraction rate may also be aided by not only the compression of the sample but also the corresponding reduction in the bed depth.

Table 2 shows the moisture content of the pressed cakes obtained from every measurement. The results show a consistent decrease in the moisture content with increased applied voltage for all samples. Similar results were also reported by Chen et al., ${ }^{[15]}$ who investigated the use of electroosmotic dewatering on vegetable sludge. Weber et al. ${ }^{[30]}$ developed a simple mathematical model, which predicted these phenomena, i.e., increased voltage results in an increased removal of water. The average reduction in moisture is $7.15 \%$ for BSG, $16.90 \%$ for melon, $6.85 \%$ for mango, $8.56 \%$ for orange, and $12.09 \%$ for cauliflower respectively (Table 2). Cauliflower and melon show the highest reduction in moisture content and this might be due to their higher electrical conductivity $(\mathrm{S} / \mathrm{m})$ as shown in Table 1. If the water is expressed as a volume reduction and proportion of the sample it may be due to a combination of both; however, all samples were pre-treated in the same manner, thus the higher water content samples

TABLE 1

Proximate analysis of food by-products studied (wet basis)

\begin{tabular}{lccccc}
\hline Parameters & Brewer's spent grain & Orange peel & Melon peel & Mango peel & Cauliflower trimming \\
\hline Moisture content (\%) & 78.2 & 77.2 & 91.0 & 79.8 & 92.2 \\
Electrical conductivity (s/m) & 0.1 & 0.2 & 0.4 & 0.2 & 0.4 \\
Protein (\%) & 4.8 & 0.7 & 0.8 & 0.5 & 2.0 \\
Fat (\%) & 2.1 & 0.2 & 0.2 & 0.3 & 0.3 \\
Ash (\%) & 0.8 & 0.6 & 0.6 & 0.5 & 0.1 \\
Fibre (\%) & 14.0 & 1.8 & 1.2 & 1.9 & 2.5 \\
pH & 4.2 & 4.1 & 5.1 & 3.7 & 6.4 \\
\hline
\end{tabular}




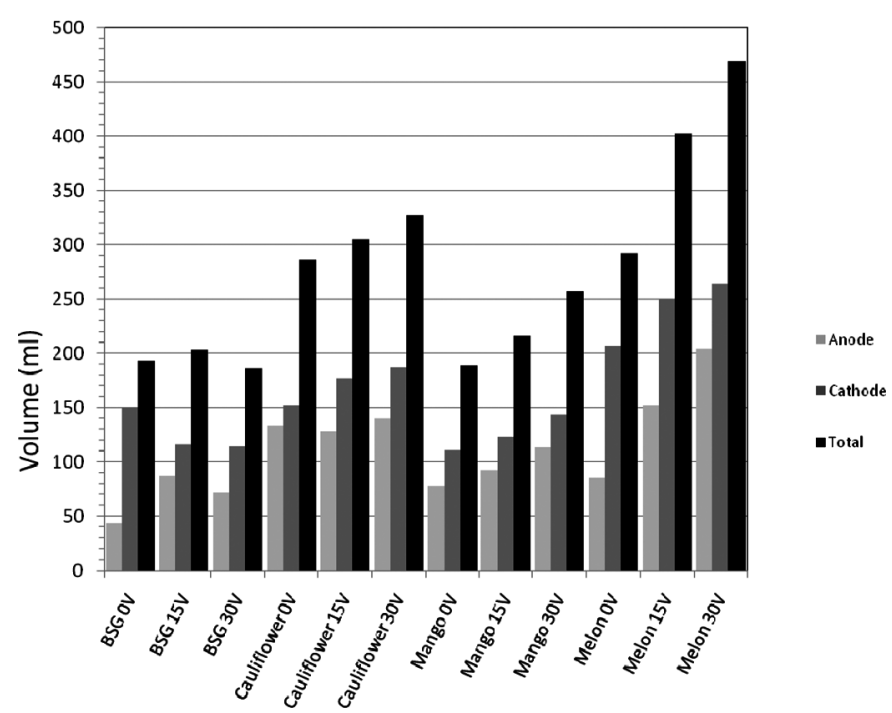

FIG. 2. Effluent discharged (g) at the anode, cathode, and in total for each sample at each voltage applied.

is how it is in real life. The difference between the start and the control is probably due to mechanical action, and the difference between the control end point and the $15 \mathrm{~V}$ end point is as a result of the EK being applied to the sample. This allows comparisons to be drawn within a sample stream. The connection between streams is probably more difficult as sample changes. Samples with higher conductivity allow more ions to migrate towards the oppositely charged electrode, which transfers momentum to the surrounding pore fluid molecules. This ion migration causes electro-osmotic flow, which contributes to the success of the electro-kinetic dewatering process. Mango and BSG showed the lowest reduction, which correlates with their electrical conductivity $(\mathrm{S} / \mathrm{m})$ values. The moisture reduction of every sample showed a correlation $\left(\mathrm{R}^{2}=0.83\right)$ with their respective electric conductivity value. This suggested that the conductivity measurement might be a good indicator to conclude how well electro-kinetic method can

TABLE 2

Moisture content of samples before and after electro-kinetic dewatering at various voltages (mean values)

\begin{tabular}{lcccc}
\hline & \multicolumn{4}{c}{ Moisture content (\%) } \\
\cline { 2 - 5 } Sample & Initial & $0 \mathrm{~V}$ & $15 \mathrm{~V}$ & $30 \mathrm{~V}$ \\
\hline Brewer's spent grain & 78.2 & 74.5 & 73.4 & 71.0 \\
Melon peel & 91.0 & 79.4 & 76.7 & 74.1 \\
Mango peel & 79.8 & 75.2 & 74.2 & 72.9 \\
Orange peel & 77.2 & 73.4 & 71.2 & 68.6 \\
Cauliflower trimming & 92.2 & 84.1 & 83.1 & 80.2 \\
\hline
\end{tabular}

dewater a particular food waste. However, the electrical conductivity is not the only parameter that determines the efficiency of dewatering. Other parameters, such as the composition of the food, which affect the water binding capacity of each sample, will also determine the dewatering efficiency. For example, fiber is well known for its high water holding and binding capacity. Fibre can directly bind water in a number of ways ${ }^{[31]}$ and material with high fiber content should show a higher resistance towards EK dewatering. Besides fiber, protein also can increase the water-holding capacity of a sample. Generally, the water held in protein structure can be divided into two main types: 1) the part bound to the molecule and is no longer available as a solvent; and 2) the part trapped in the protein matrix or a corresponding co-matrix (polysaccharide, fat). The first type can be regarded as absorbed water and the second as retained water. In most cases, the water-holding capacity of a protein matrix is determined by both the amount of absorbed and retained water. ${ }^{[32]}$ The waterholding capacity of protein depends not only on pore and capillary size but also on the charge of the protein molecules (hydrophobic interactions, hydrogen bonds, S-S bonds, acids, bases as well as van der Waals' forces). In addition to these parameters, the surrounding medium may also affect the protein due to its ionic strength, ion species, $\mathrm{pH}$ condition, and temperature. ${ }^{[32]}$ These imply that a clear understanding of the water-holding capacity of a substance can only be achieved by studying its physiochemical behavior as well as its microstructure. In this study, conductivity appears to be dominant as no correlation with fiber and protein as anticipated was established.

\section{Power Consumption}

The total power consumption of electro-kinetic dewatering can be calculated as the sum of electrical power consumed by applied voltage across the sample and the mechanical power applied by the hydraulic pressure ram. In this discussion, a comparison of the total power consumption during electro-kinetic dewatering and conventional thermal drying process is made. The theoretical calculated energy required for thermal removal of water was determined using a value of $43 \mathrm{~kJ} \mathrm{~mol}^{-1}$, as quoted by Al-Asheh et al. ${ }^{[16]}$ The theoretical energy required to remove the same amount as removed during EK by thermal energy is as shown in Table 3. These theoretical values assume $100 \%$ energy transfer efficiency by the heating mechanism (oven, hot plate, etc.), although the efficiencies are in reality much less than this.

The power consumed in applying a constant pressure of $75 \mathrm{kPa}$ to the material being dewatered was estimated from the maximum volume displacement of the cell recorded during all of the trials carried out (Equation 1). This is in some cases an over-estimate of the energy used as less displacement was recorded in some samples. While the 
TABLE 3

Comparison of power consumption during EK dewatering and thermal drying

\begin{tabular}{lcccccc}
\hline & \multicolumn{7}{c}{ Energy $(\mathrm{KW} \mathrm{h})$} \\
\cline { 2 - 7 } Sample & Thermal & Pressure $+0 \mathrm{~V}$ & Thermal & Pressure $+15 \mathrm{~V}$ & Thermal & Pressure $+30 \mathrm{~V}$ \\
\hline BSG & 0.05 & $5.8 \times 10^{-5}$ & 0.06 & 0.001 & 0.08 & 0.004 \\
Melon & 0.19 & $5.8 \times 10^{-5}$ & 0.20 & 0.007 & 0.22 & 0.019 \\
Mango & 0.06 & $5.8 \times 10^{-5}$ & 0.07 & 0.005 & 0.08 & 0.020 \\
Orange & 0.05 & $5.8 \times 10^{-5}$ & 0.07 & 0.004 & 0.09 & 0.012 \\
Cauliflower & 0.17 & $5.8 \times 10^{-5}$ & 0.18 & 0.006 & 0.20 & 0.027 \\
\hline
\end{tabular}

calculation makes no allowance for the efficiency of the system, the energy involved in this process is so low that, even at a very low efficiency, EK dewatering would still compare favorably with thermal drying.

The total power consumed by the applied voltage is calculated using Equation (2). In each measurement, the current flow through the sample is noted for 15 minutes. During this period, the electrical resistance increases gradually as the amount of water in each sample is reduced and subsequently the current across the sample is also reduced. The current value is used to calculate the total power consumption of every sample.

For all experiments, an increase in the voltage supply resulted in power increase consumption per unit water removed. Table 3 shows the energy required to dewater the sample at 15 and $30 \mathrm{~V}$. The thermal column of each section represents the equivalent energy needed to remove the amount of water from each sample by thermal drying. Figure 3 shows the ratio between the thermal energy and EK energy needed to remove the same amounts of water from each sample. This plot shows that the theoretical calculated energy required for thermal removal of equal amounts of water are significantly higher than the energy required by electro-kinetic dewatering. BSG showed the highest differences while orange shows the smallest ratios across the range of voltage applied. Higher voltage did not

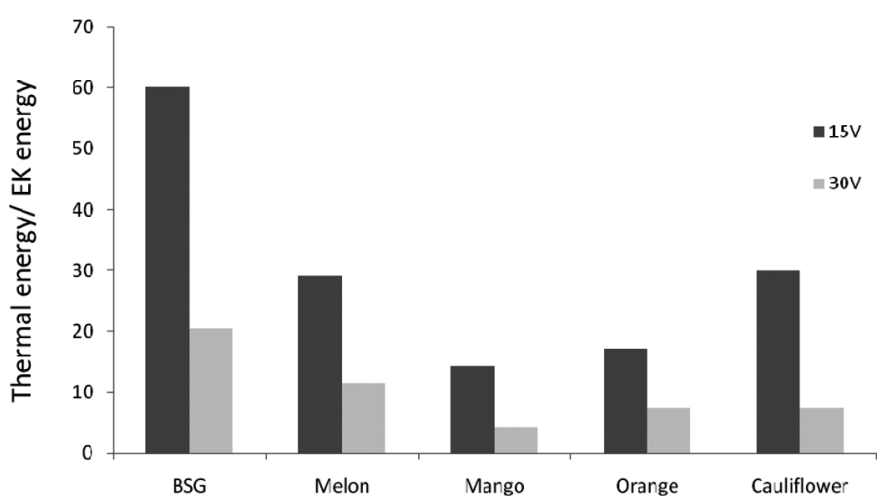

FIG. 3. Electro-kinetic dewatering efficiency at 15 and $30 \mathrm{~V}$. show an increase in dewatering efficiency. Energy is wasted in joule heating (specific heat capacity) and providing heat of vaporization for phase change of water rather than favoring the more efficient electro-osmosis process. This is observed during the measurement when the temperature of the sample increases with higher applied voltage. Although melon peel has almost the same conductivity as the cauliflower sample, the recorded current flow through the sample decreased rapidly with time compared to cauliflower samples. Thus, the total power consumption is less than that seen in the cauliflower sample. It seems that electro-kinetic dewatering performance is dependent upon the type of food by-product applied. However, this work is still in progress using different voltages and different food wastes. The chemical composition of the food materials will be also taken into consideration. Despite the variation between samples, electrokinetic dewatering presents an energy efficient alternative to convection drying and is relatively quick when compared with other drying techniques. Shukla and Singh ${ }^{[17]}$ studied the use of osmo-convective drying as a method for improving efficiency when drying cauliflower, mushroom, and green pea. Their study showed a significant reduction in the energy required to dry the products (when compared with solar and convective methods), along with improvements in color and microbial load. However, despite the energy reduction, the process is time-consuming and no consideration is given to dealing with the solutions remaining after drying. Thus, electrokinetic dewatering may be considered to have distinct advantages over other process, including osmo-convective drying.

\section{Effluent $\mathbf{p H}$}

Table 4 shows the $\mathrm{pH}$ measured at both cathode and anode for each sample at 0,15 , and $30 \mathrm{~V}$. Generally, the effluents discharged from the cathode show higher $\mathrm{pH}$ compared to the effluents discharged from the anode after the dewatering process. This is due to the accumulation of $\mathrm{H}^{+}$at anode and $\mathrm{OH}^{-}$at cathode during electrolysis of water. Higher voltage increases the concentration of both $\mathrm{H}^{+}$at anode and $\mathrm{OH}^{-}$at cathode. Assuming that only water is electrolyzed, the $\mathrm{pH}$ alteration gives a good 
TABLE 4

$\mathrm{pH}$ of effluent (cathode and anode) of by-product sample

\begin{tabular}{|c|c|c|c|c|c|c|}
\hline \multirow[b]{3}{*}{ Food waste } & \multicolumn{6}{|c|}{$\mathrm{pH}$ of effluent discharged } \\
\hline & \multicolumn{2}{|c|}{$0 \mathrm{~V}$} & \multicolumn{2}{|c|}{$15 \mathrm{~V}$} & \multicolumn{2}{|c|}{$30 \mathrm{~V}$} \\
\hline & Cathode $(-)$ & Anode $(+)$ & Cathode $(-)$ & Anode $(+)$ & Cathode $(-)$ & Anode $(+)$ \\
\hline Brewer's spent grain & 4.2 & 4.2 & 4.3 & 4.2 & 4.5 & 4.2 \\
\hline Melon peel & 5.1 & 5.1 & 5.9 & 4.4 & 6.2 & 4.2 \\
\hline Mango peel & 3.8 & 3.8 & 3.9 & 3.4 & 4.2 & 3.2 \\
\hline Orange peel & 4.1 & 4.1 & 4.3 & 4.0 & 4.4 & 4.0 \\
\hline Cauliflower trimming & 6.4 & 6.4 & 6.5 & 4.7 & 7.0 & 4.0 \\
\hline
\end{tabular}

indication on the amount of water electrolyzed and released as gas during the dewatering process. This gives another dimension for a detailed analysis of the dewatering process in terms of water removed by electrolysis, applied pressure, and the voltage gradients.

\section{CONCLUSION}

An experimental system to study electro-osmotic combining mechanical dewatering of different food byproducts has been developed. The system was used to characterize electro-kinetic dewatering under constant pressure and constant voltage conditions. It was found that at constant voltage and pressure the water removed increases with the magnitude of the voltage applied across the sample. The performance of EK process is also dependent upon other parameters such as the conductivity and the composition of each material. Samples with higher electrical conductivity show higher dewatering efficiency. Correlation between conductivity and current indicated that samples with higher conductivity allow elevated current flow, which encourages the electro-osmotic flow within the sample. The power consumption of the electro-kinetic dewatering was found to be significantly lower than conventional drying methods. This study shows that electrokinetic dewatering of food by-products is feasible technically and has the potential as an economical predrying process to reduce moisture content of food waste. Thus, electro-kinetic dewatering should be given serious consideration for future dewatering application within the food industries.

\section{ACKNOWLEDGMENT}

The authors would like to acknowledge DEFRA for funding a project.

\section{REFERENCES}

1. Morley, N.; Bartlett, C. Mapping Waste in Food Industry for DEFRA and the Food and Drink Federation; Oakdene Hollins: Aylesbury, UK, 2008.
2. Stojceska, V.; Ainsworth, P.; Plunkett, A.; İbanoğlu, S. The recycling of brewer's processing by-product into ready-to-eat snacks using extrusion technology. Journal of Cereal Science 2008, 47, 469-479.

3. Stojceska, V.; Ainsworth, P.; Plunkett, A.; İbanoğlu, E.; İbanoğlu, S. Cauliflower by-products as a new source of dietary fibre, antioxidants and proteins in cereal based ready-to-eat expanded snacks. Journal of Food Engineering 2008, 87(4), 554-563.

4. Gremmen, B.; van Haperen, P.; Lamerichs, J. In A Socio-economic Perspective on Co-product Exploitation. Total Food- Sustainability of the Agri-Food Chain; Waldron, K.W., Moates, G.K., Fraulds, C.B., Eds.; The Royal Society of Chemistry: Cambridge, UK, 2009; 3-13.

5. Mihoubi, D. Mechanical and thermal dewatering of residual sludge. Desalination 2004, 167(1-3), 135-139.

6. Wakeman, R.J. Separation technologies for sludge dewatering. Journal of Hazardous Materials 2007, 144(3), 614-619.

7. Chung, L.L.; Shivram, W.S.; Narayan, T.B.; Sadashiv, M.A. Advances and recent developments in thermal drying for bio-origin and agricultural products. Stewart Postharvest Review 2008, 4(1), 1-23.

8. Kearney, R.J.; Bolin, K.M.; Dooley, B. New thermal treatment technology will energy efficiently convert biosolids to a renewable fuel: Paper \#39. 27th Annual International Conference on Thermal Treatment Technologies, Montreal, Canada, May 12-16, 2008.

9. Mujumdar, A.; Zhonghua, W. Thermal drying technologies Cost-effective innovation aided by mathematical modeling approach. Drying Technology 2008, 26(1), 146.

10. Beke, J.; Vas, A.; Mujumdar, A.S. Impact of process parameters on the nutritional value of convectively dried grain. Drying Technology 1993, 11(6), 1415-1428.

11. Grabowski, S.; Mujumdar, A.S.; Ramaswamy, H.S.; Strumillo, C. Osmo-connective drying of grapes. Drying Technology 1994, 12(5), 1211-1219.

12. Acar, Y.B.; Alshawabkeh, A.N.; Gale, R.J. Fundamentals of extracting species from soils by electrokinetics. Waste Management 1993, 13(2), 141

13. Yeung, A.T.; Sadek, S.M.; Mitchell, J.K. New apparatus for the evaluation of electro-kinetic processes in hazardous waste management. Geotechnical Testing Journal 1992, 15(3), 207-216.

14. Yeung, A.T.; Mitchell, J.K. Coupled fluid, electrical and chemical flows in soil. Geotechnique 1993, 43(1), 121-134.

15. Chen, H.; Mujumdar, A.; Raghavan, G. Laboratory experiments on electroosmosis dewatering of vegetable sludge and mine tailings. Drying Technology 1996, 14, 2435-2445.

16. Al-Asheh, S.; Jumah, R.; Banat, F.; Al-Zou'bi, K. Direct current electroosmosis dewatering of tomato paste suspension. Food and Bioproducts Processing 2004, 82, 193-200. 
17. Shukla, B.D.; Singh, S.P. Osmo-convective drying of cauliflower, mushroom and green pea. Journal of Food Engineering 2007, 80, 741-747.

18. Krishnaswamy, P.; Klinkwoski, P. Advances in Solid-Liquid Separation; Battelle Press: Columbus, OH, 1986.

19. El-Shafey, E.I.; Gameiro, M.L.F.; Correiaa, P.F.M.; de Carvalhoa, J.M.R. Dewatering of brewer's spent grain using a membrane filter press: A pilot plant study. Separation Science and Technology 2004, 39, 3237-3261.

20. Manthey, J.A.; Grohmann, K. Concentrations of hesperidin and other orange peel flavonoids in citrus processing byproducts. Journal of Agricultural and Food Chemistry 1996, 44(3), 811-814.

21. Ma, E.; Cervera, Q.; Mejía Sánchez, G.M. Integrated utilization of orange peel. Bioresource Technology 1993, 44(1), 61-63.

22. Liu, Y.; Shi, J.; Langrish, T.A.G. Water-based extraction of pectin from flavedo and albedo of orange peels. Chemical Engineering Journal 2006, 120(3), 203-209.

23. FAOSTAT. FAO Statistics. Food and Argriculture Organisation of the United Nations: Rome, Italy, 2007.

24. Ajila, C.M.; Leelavathi, K.; Prasada Rao, U.J.S. Improvement of dietary fiber content and antioxidant properties in soft dough biscuits with the incorporation of mango peel powder. Journal of Cereal Science 2008, 48(2), 319-326.
25. Wadhwa, M.; Kaushal, S.; Bakshi, M.P.S. Nutritive evaluation of vegetable wastes as complete feed for goat bucks. Small Ruminant Research 2006, 64(3), 279-284.

26. AOAC. Official Methods of Analysis; Williams, S.; Ed.; AOAC: Washington, DC, 1984.

27. Gertz, C.; Fiebig, H.J. Determination of Fat Content by the Caviezel Method (Rapid Method). European Journal of Lipid Science and Technology 2000, 102(2), 154-158.

28. BS1377-3: 1990. Methods of Testing Soils For Civil Engineering Purposes.

29. Banerjee, S.; Law, S.E. Electroosmotically enhanced drying of biomass. IEEE Transactions on Industry Applications 1998, 34(5), 992-999.

30. Weber, M.E.; Witwit, S.M.; Mujumdar, A.S. A model for electroosmotic dewatering under constant voltage. Drying Technology, 1987, 5(3), 467-474.

31. Martin, F. Fibre and water binding capacity. Proceedings of the Nutrition Society 2003, 62, 223-227.

32. Kneifel, W.; Paquin, P.; Abert, T.; Richard, J.-P. Water-holding capacity of proteins with special regard to milk proteins and methodological aspects-A review. Journal of Dairy Science 1991, 74, 2027-2041. 